\title{
Los operadores causativos conversos y su evolución en español
}

\author{
Converse causative operators and their evolution in the Spanish language
}

\begin{abstract}
Rafael García Pérez
Universidad Carlos III de Madrid, Departamento de Humanidades, Comunicación y Documentación, Madrid, España. Correo electrónico: rafael.garcia.perez@uc3m.es
\end{abstract}

En este trabajo se estudia un grupo concreto de verbos dentro de los llamados operadores causativos: los operadores causativos conversos u operadores consecutivos, estrechamente vinculados a los operadores causativos. Se muestra, desde el punto de vista sintácticosemántico, que estos verbos comparten una misma estructura: seleccionan predicados en función de sujeto, interpretados como una consecuencia, y en función de complemento de régimen, predicados interpretados, a su vez, como la causa que da lugar a esa consecuencia. Desde el punto de vista histórico, se pone de manifiesto que estos operadores son el resultado de distintos procesos de metaforización, procesos que no siempre resultan perceptibles hoy en día en la misma medida, y se describe su proceso de introducción en nuestra lengua.

Palabras clave: operadores causativos, operadores causativos conversos, operadores consecutivos

This paper studies a group of verbs closely linked to the so-called causative operators: 'converse causative operators' or 'consecutive operators'. From the syntactic-semantic point of view, we show that these verbs share the same structure: they select a subject and a prepositional object; the subject function is performed by predicates interpreted as a consequence, and prepositional object function, by predicates interpreted as a cause. From the historical point of view, we highlight that these operators are the result of different metaphorical processes, which nowadays are not always noticeable to the same extent. The process of their introduction in Spanish is also described.

Key words: causative operators, converse causative operators, consecutive operators

\section{INTRODUCCIÓN}

En otro lugar (Pascual y García Pérez 2007: 28-33) pusimos de manifiesto la necesidad de contar con una clasificación previa de las palabras de una lengua, sobre todo basada en criterios sintáctico-semánticos, para garantizar un tratamiento más homogéneo desde un punto de vista lexicográfico y una descripción más refinada de 
los procesos de cambio que se han producido a lo largo de la historia. En ese sentido, he venido mostrando, especialmente en el campo verbal, que las clasificaciones llevadas a cabo por la teoría del Léxico-gramática y, más concretamente, la teoría de las Clases de objetos aplicada a los diccionarios electrónicos, han aportado soluciones dignas de tenerse en cuenta también en el estudio histórico del léxico (vid., por ejemplo, García Pérez 2005 para el caso de los verbos de apoyo).

Entre los seis grandes grupos verbales que han de considerarse en una primera clasificación, ${ }^{1}$ están los llamados operadores, es decir, aquellos verbos que operan o actúan sobre determinados predicados de primer orden para introducir un nuevo argumento. Dentro de este grupo se han estudiado con especial profundidad los llamados operadores causativos y sus extensiones (término de M. Gross 1981), hasta el punto de que, en algunos trabajos, ha sido bastante habitual la identificación de los términos operador y operador causativo. No obstante, el concepto de operador es más complejo de lo que a primera vista parece. A continuación trataré un grupo de verbos que, aunque no han recibido mucha atención por parte de los lingüistas, se hallan directamente relacionados con los operadores causativos y que podríamos considerar, desde un punto de vista puramente semántico, siguiendo la terminología de Cruse, ${ }^{2}$ como “conversos”.

\section{LOS OPERADORES CAUSATIVOS CONVERSOS}

Como he apuntado más arriba, los operadores causativos operan sobre una oración simple $e^{3}$ añadiendo un nuevo argumento al que atribuyen, semánticamente, el rasgo 'causa'. Esa oración simple puede estar formada por un verbo pleno o por un sustantivo predicativo actualizado por un verbo de apoyo; en el ejemplo siguiente (2), "la actitud de Juan” se introduce como nuevo sujeto de la oración de base (1) “La mayoría abandonó la sala”, que conserva el verbo distribucional o pleno:

(1) La mayoría abandonó la sala

(2) La actitud de Juan hizo \# La mayoría abandonó la sala à La actitud de Juan hizo que la mayoría abandonara la sala.

En (4), por el contrario, el operador causativo actúa sobre una oración con sustantivo predicativo y verbo de apoyo (tener), lo que implica una desaparición del este último en la oración causativa resultado del proceso de transformación:

(3) Mario tiene miedo

(4) La actitud de Juan da \# Mario tiene miedo à La actitud de Juan da miedo a Mario.

G. Gross (2001), entre otros: verbos distribucionales o plenos, verbos de apoyo, operadores, pro-verbos, verbos auxiliares y verbos constituyentes de locuciones verbales.

2 Cruse (2004: 167-168) estudia los opuestos como una macroclase semántica que incluye, a su vez, los antónimos en sentido estricto, los “complementarios”, los “reversos” y los “conversos”. También G. Gross (1987) ha hablado de estructuras conversas en el caso de los verbos de apoyo.

3 Sigo la idea de que hay tantas oraciones simples como predicados (M. Gross 1981). Para la diferencia entre predicados y argumentos, vid. G. Gross $(1993,1996)$. Sorprende que la Nueva Gramática de la RAE no tenga en cuenta esta distinción primaria, aunque es consciente del carácter predicativo de muchos sustantivos y adjetivos. 
El nuevo argumento introducido por el operador es un sujeto, en general, oracional, como hemos visto en (2), pero no está excluida la posibilidad de que sea humano, si bien se interpreta, muy frecuentemente, como metonimia de un predicado subyacente:

(5) $\left[\right.$ Juan = la actitud de Juan] da miedo a Mario. ${ }^{4}$

El número de operadores causativos es bastante amplio, pues, junto a los operadores básicos, como hacer, dejar o dar, hemos de tener en cuenta también sus extensiones aspectuales, de carácter metafórico en la mayor parte de los casos y, como tuve ocasión de mostrar al estudiar la formación de la clase de predicados <odio> (García Pérez 2006), dotadas de interesantes restricciones de selección no siempre estables a lo largo de la historia. Así, se puede atizar el odio pero no *atizar una dolencia; dar miedo pero no *hacer miedo; sembrar el terror, pero no sembrar la pasión etc. ${ }^{5}$ Se puede decir que, en sus restricciones combinatorias, los operadores causativos se acercan formalmente a los verbos de apoyo, con los que, sin embargo, no deben confundirse, ya que estos últimos son sólo unidades actualizadoras de los predicados nominales o adjetivos a los que acompañan (carecen, por tanto, de valor predicativo).

Desde un punto de vista semántico, el estudio del corpus histórico nos revela determinadas unidades verbales que se presentan como opuestas a los operadores causativos, aunque de un modo un tanto particular: aparecen como una especie de sinónimos desde el punto de vista puramente referencial, pero condicionados por una inversión en el orden de sus elementos. ${ }^{6}$ Mientras los operadores causativos introducen un nuevo sujeto que hemos de considerar la causa de la acción, estado o acontecimiento de base al que se aplican, estos operadores sitúan la consecuencia, es decir, la acción, estado o acontecimiento de base, en la posición del sujeto. Alteran, por tanto, la percepción del orden lógico de los sucesos, dando primacía a las consecuencias sobre las causas. De ahí que me haya decidido a denominarlos operadores causativos conversos u “operadores consecutivos”. Veamos el ejemplo (6) a continuación:

(6) [...] el accidente se debió a la explosión anticipada de un proyectil antiaéreo.

El sujeto accidente es un predicado no actualizado que se presenta como la consecuencia del complemento de régimen la explosión anticipada de un proyectil antiaéreo, reducción de la oración simple actualizada un proyectil antiaéreo sufrió una explosión. Tendríamos, por tanto, dos oraciones simples enlazadas por la relación consecutiva que impone el operador deberse:

\footnotetext{
Eso no impide que en algunos casos, como ha señalado G. Gross (2001), el sujeto humano puede interpretarse como agentivo.

5 En ese sentido, también como los verbos de apoyo, pueden diferir entre lenguas próximas con mucha facilidad: dar miedo (esp) frente a faire peur (fr.), por ejemplo.

6 No se han tenido en cuenta en los trabajos dedicados a los verbos causativos del español, ni siquiera en aquellos, como el de M. Alfonso Vega (2006), que estudian la causatividad desde el punto de vista histórico.
} 
(6.1) Un proyectil antiaéreo sufrió una explosión anticipada

(6.2) Se produjo el accidente

(6.3) El accidente se debió \# Un proyectil antiaéreo sufrió una explosión anticipada

(6.4) El accidente se debió a la explosión anticipada de un proyectil antiaéreo

La utilización de un operador causativo habría permitido expresar la misma realidad aunque en un orden lineal diferente:

(7) La explosión anticipada de un proyectil antiaéreo causó el accidente.

(7.1) Un proyectil antiaéreo sufrió una explosión anticipada > la explosión anticipada de un proyectil antiaéreo

(7.2) Se produjo el accidente

(7.3) La explosión anticipada de un proyectil antiaéreo causó \# Se produjo el accidente

(7.4) La explosión anticipada de un proyectil antiaéreo causó el accidente

Los operadores causativos conversos constituyen un grupo bastante homogéneo dentro de los operadores causativos, aunque su número no sea muy elevado y no siempre lexicalicen esta información sintáctico-semántica con la misma visibilidad. Como veremos a continuación, hemos de contar, por un lado, con unos verbos que llamaré "neutros", por el hecho de que, en la actualidad, los procesos de extensión de significado que han conducido a su constitución resultan más bien opacos; $y$, por otro, con operadores metafóricos, caracterizados por el hecho de que aún se interpretan, en mayor o medida, como extensiones metafóricas de otras unidades léxicas de base. Dentro de estos últimos, analizaré algunos verbos de movimiento y de cambio de estado que se han prestado con mayor facilidad a este tipo de evolución.

\section{OPERADORES DE CARÁCTER NEUTRO}

Se trata de los verbos redundar, resultar y deberse (a). Pese a haber perdido, en cierta medida, el sentido metafórico que permitió su formación como operadores causativos conversos, no son, necesariamente, los más antiguos.

3.1. El verbo redundar es un cultismo introducido en castellano en el siglo XIV a partir de la forma latina REDUNDARE que, como muy bien explica el DECH, era ya un derivado de UNDA 'ola' en el propio latín, con el significado de 'desbordarse', 'abundar' e, incluso 'caer de rechazo sobre alguno'. Dado el sentido metafórico que había adquirido en la lengua latina, se entiende fácilmente que su incorporación al castellano privilegiara las extensiones semánticas y que los primeros testimonios ${ }^{7}$ nos revelen un uso como operador causativo que se ha mantenido hasta nuestros días.

Estos primeros testimonios son de textos aragoneses, lo que no es de extrañar, si pensamos que muchos cultismos pudieron pasar por los dialectos orientales en un momento en que la traducción tenía un gran apogeo en el reino de Aragón (Lapesa 1981: 256). 
En este uso como operador, el verbo redundar seleccionaba un sujeto oracional y un complemento de régimen precedido de la preposición en:

[...] et si alguno de los ditos assi dampnificados vexados agreviados siquiere injuriados hauran proseguir et acusar el dito çalmedi segunt el dito fuero por impotencia o por otra causa hurian de lexar la dita prosecucion et acusacion desuso ditas et aquesto si non si subvenia de condecent remedio redundaria en grant danyo de aquellos et seria considerado esto perdimiento de justicia [...] (Ordinación dada a la ciudad de Zaragoza, 1391).

La constatación de esta temprana utilización como operador causativo resulta enormemente interesante, porque constituye una prueba documental de la consideración de opuesto semántico que tienen los operadores causativos conversos. De hecho, partiendo de este uso más general como operador causativo se entiende mejor la formación, un poco más tarde, de una estructura causativa conversa por inversión del orden de los elementos y cambio de régimen preposicional. Así, en el siglo XV, el verbo redundar empieza a seleccionar ya como sujeto la consecuencia y como complemento precedido de la preposición de, la causa. En principio, la oración que constituía el sujeto (la consecuencia) estaba formada por un predicado nominal de estado, preferentemente los sustantivos daño, provecho, beneficio, gloria y virtud:

Pero como vuestra serenidad puede considerar, el daño que a nuestros subditos y rentas reales redundara de la dicha expulsion y prohibicion de comercio de venecianos es grande (Anónimo, 1483).

La extensión del sujeto a otro tipo de estructuras oracionales se produce a partir del siglo XVI. Se puede decir, por tanto, que el operador causativo converso se volvió más genérico:

E desde a diez o doce días, vinieron los indios de Taragoaco, que es donde los cristianos hobieron la primera guazábara o batalla, e venían de paz, e asentaron sus amistades con el gobernador. E cada día venían otros a lo mismo; lo cual redundaba de la buena maña e recaudo que el gobernador se daba en tractar a los indios (Gonzalo Fernández de Oviedo, 1535-1557).

Esto hizo que en el paradigma de los sustantivos predicativos seleccionados como sujeto pudieran aparecer también acciones y acontecimientos, aunque los ejemplos no son muy numerosos:

[...] y que habiendo acudido su persona al remedio, se vido en manifiesto peligro de perder la vida, pues lo hirieron muy mal; redundando de esto otros alborotos y pendencias muy sangrientas [...] (Bartolomé Arzans de Orsúa y Vera, 1702-1736)

En el caso del complemento, los sustantivos predicativos no actualizados, sin demasiadas restricciones (sustantivos de estado, acción o acontecimiento), fueron los primeros elementos seleccionados (s. XV):

Pero como vuestra serenidad puede considerar, el daño que a nuestros subditos y rentas reales [Anterior]redund[Siguiente]ara de la dicha expulsion y prohibicion de comercio de venecianos es grande, y principalmente en el reyno de Sicilia [...] (Anónimo, 1483). 
Un poco más tarde, en el siglo XVI, encontramos también oraciones subordinadas de infinitivo o subordinadas completivas introducidas por la conjunción que. Esta selección, sin embargo, no se extendió demasiado en el tiempo; de hecho, no tuvo éxito más allá de los Siglos de Oro.

[...] y el general daño que los pueblos Santa Fee, Tunja y Velez les venia y redundava de que la çiudad de la Trinidad no permaneçiese donde estava, y ansi, por las cavsas dichas, como por ser vno de los primeros y arduos negoçios que se le ofrecian en la tierra, el dotor Venero deseo poner rremedio en ello [...] (Fray Pedro de Aguado, 1573-1581).

El uso de redundar como operador causativo converso decayó notablemente a partir del siglo XVIII. En la actualidad, se puede considerar prácticamente desaparecido, salvo que se recurra a él como arcaísmo y con intención marcadamente estilística. ${ }^{8}$

3.2. Resultar es también un cultismo; procede del latín RESULTARE 'resurtir, rebotar', derivado de SALTARE (DECH). Como cultismo, se incorporó relativamente tarde al léxico español (siglo XIV), pero su uso está muy ligado, casi desde el principio, a la función de operador causativo converso..$^{9}$ Su incorporación al paradigma de los operadores causativos directos fue un tanto más tardía, lo que resulta difícil de explicar, especialmente si tenemos en cuenta, como hemos visto más arriba, que redundar llevaba ya un tiempo desempeñando esta función. Solo desde la segunda mitad del siglo XV seleccionó el verbo resultar un complemento precedido de la preposición en..$^{10}$ El siguiente ejemplo podría ser una buena muestra de su paralelismo con el operador más antiguo:

[...] salvo temiendo quel odio quel rey avia al marques, su padre, e a doña Maria de Mendoça, su hermana, no oviese todo de resultar en su daño (Crónica de Enrique IV de Castilla, 1481-1482)

Como operador causativo converso, pues, hizo irrupción con cierta prontitud en la historia de nuestra lengua (comienzos del siglo XV); regía, al igual que en nuestros días (y en paralelo con su sinónimo redundar) dos predicados: un sujeto (la consecuencia) y un complemento de régimen preposicional con de (la causa). Los primeros ejemplos muestran una preferencia por la selección de sustantivos predicativos no actualizados en función de sujeto y, entre ellos, sustantivos de estado:

Primeramente mostraré en general e en comun, las virtudes e utilidades e loables effectus que resultan de las honestas delettaçiones e loables deportes e exerçiçios... (Rodrigo Sánchez de Arévalo, 1454-1457).

8 No encuentro ejemplos en el CREA. Los lingüistas, en general, no dan cuenta de ella. Náñez (1995) o Cano (1999), por ejemplo, no mencionan la variante sintáctica redundar de y sí redundar en.

9 Muy cerca, aunque no pueda considerarse operador en este caso, se halla el sentido de deducción, que supone una extracción de conclusiones en el ámbito argumentativo. La utilización del verbo resultar tenía como ventaja presentar dichas conclusiones como un hecho impersonal, vinculado a la propia naturaleza de las cosas y, por tanto, ajeno a la intervención del orador, lo que reforzaba su valor de convicción. No sorprende, pues, que los primeros testimonios de este uso deductivo se remonten también al siglo XIV: "Pues resulta de lo suso dicho que deven ser los consegeros virtuosos y de buenas costumbres (Rodrigo Sánchez de Arévalo, 1454-1457)”.

10 Como mera curiosidad, y teniendo en cuenta la antigüedad de esta estructura, me gustaría dejar apuntada aquí mi sorpresa por el hecho de que haya podido considerarse un anglicismo (vid. Cano 1999: 1828) 
Los restantes predicados (acción y acontecimiento), menos habituales en toda la historia del verbo, no estaban excluidos, aunque empiezan a formar parte del paradigma a partir del siglo XVI:

[...] dando cuenta dello al sacerdote, él le truxo una forma por consagrar, queriendo con esta ficción contentarle y estorvar el peligro que resultava de comulgarle loco (Alonso de Villegas, 1594)

También tuvieron su origen en los Siglos de Oro otras estructuras oracionales, como los infinitivos y las proposiciones subordinadas completivas:

Después desto podreciósele el lado derecho, y fue de suerte que, si no era bien ligada con lienços, no podía bolverse de la otra parte sin que sus miembros se descoyuntassen, y resultó de aquí aver de estar acostada, el rostro en alto, hasta el último día de su vida, para que assí pudiesse mejor mirar y contemplar el Cielo (Alonso de Villegas, 1594).

En lo que respecta al complemento preposicional, este verbo, en su uso como operador causativo converso, seleccionó desde el principio -y en correspondencia con la selección en el sujeto- oraciones formadas por sustantivos predicativos; pero, desde muy temprano, aceptó también estructuras oracionales complejas. Así, no resultaban nada extrañas las construcciones con infinitivo:

Es insania vn furor que resulta del perder del iuzio (Alfonso de Palencia, 1490) [...] e los litigios que resultan de comprar o vender también los determinan (Gonzalo Fernández de Oviedo, 1535-1557).

Tampoco lo eran las construcciones subordinadas completivas introducidas por la conjunción que:

El gran daño que resulta de que se salga de su lugar todos lo saven (Tomé Cano, 1631)

Al igual que sucedía con los operadores causativos, resultar podía tener, con menor frecuencia, un argumento humano metonímico, aunque, para hacer honor a su carácter semánticamente converso, la metonimia afecta siempre al complemento, no al sujeto (contrariamente a los causativos), pues es requisito de ambos tipos de operadores que las consecuencias se manifiesten necesariamente como predicados. La aparición de este complemento humano metonímico es más tardía, pues se remonta a finales del siglo XVI. De esta posibilidad hizo especial uso la retórica de los Siglos de Oro:

[...] ni penetran el bien que en los hombres resulta de la mano de Dios por la reuerencia que hazen a su Madre (Fray José Sigüenza, 1600)

También desde el siglo XVI, al menos, la idea de los hablantes de que se hallan ante un verbo que lexicaliza una relación causa-consecuencia en la que se invierte el orden de los elementos llevó a que, con bastante frecuencia, se recogiera, como sustantivo predicativo, con un cierto carácter redundante, causa en el complemento preposicional: 
Y por no entenderlo se hazen muchos herrores en la aplicación de las dichas drogas, los quales resultan de las causas que en el presente capítulo diremos (Diego de Santiago, 1598).

Por analogía, consecuencia hizo su aparición en el sintagma sujeto, aunque los ejemplos son muy escasos y más tardíos:

[...] si han de evitarse las funestas consecuencias que resultarian del abandono ó interpretacion equivocada de las disposiciones superiores (Eusebio Page, 1881-1883).

Resultar, como operador causativo converso, ha estado vigente en español hasta nuestros días; se hizo muy pronto con la preferencia de los hablantes, imponiéndose al más antiguo redundar, que entrará en decadencia, como hemos visto más arriba, a partir del siglo XVIII. No obstante -y a pesar de la fuerza con que irrumpió en nuestra lengua- su uso disminuyó notablemente desde finales del siglo XIX, lo que ha ido acompañado de una mayor restricción en sus criterios de selección. En la actualidad, cuando los hablantes recurren a él, prefieren los sustantivos predicativos para la función de sujeto; para la función de complemento, además de los sustantivos predicativos, admiten también predicados nominales y, en menor medida, estructuras oracionales con infinitivo.

3.3. La variante pronominal del verbo deber, deberse (a) es, sin duda, más antigua que las formas verbales redundar y resultar, pues aparece ya en los primeros textos del castellano; ahora bien, frente a las anteriores, carece de una variante sintáctica que desempeñe la función de operador causativo directo, y su uso como operador causativo converso ha de considerarse relativamente tardío. Durante toda la Edad Media, deberse (a) se presenta solo con un sentido pasivo del significado más primario 'adeudar'. Solo a finales del siglo XVI, empezamos a encontrar ejemplos de su sentido consecutivo: en un primer momento, admite sujetos y complementos cuyo núcleo estaba constituido por sustantivos predicativos no actualizados:

Lo que yo y cuantos hay en el mundo deseamos saber es qué temperamento se debe a la complexión de la naturaleza humana, y en qué grado y armonía estén los humores en él (Juan de Pineda, 1589).

Estos sustantivos predicativos no estaban especialmente restringidos; con este operador se combinaban tanto sustantivos de acción, como de estado y acontecimiento. Si en el ejemplo anterior el sujeto que actúa como consecuencia constituye un estado, en los dos siguientes encontramos una acción y un acontecimiento respectivamente:

Vos, señor, al fin vencistes, que son los reyes planetas, y las obras del vasallo se deben a su influencia.

(Juan Ruiz de Alarcón, 1619) 
Fuerte es la Parca, pero tú más fuerte; no se debió a su golpe tu caída;

[...]

(Gabriel Bocángel, 1617).

Los sustantivos causa y consecuencia aparecieron tarde como núcleo del sintagma preposicional y del sintagma sujeto respectivamente; si en el caso del verbo resultar, esta selección se remonta al siglo XVI, al menos para el primero de los predicados, en el caso del operador deberse ( $a$ ) hemos de esperar hasta el siglo XIX:

Las alternativas de actividad y de estancación de la industria moderna, que se atribuyen a la introducción de las máquinas, se [Anterior]deb[Siguiente]en a otras causas, que estudiaremos al tratar de las crisis industriales [...] (Mariano Carreras y González, 1881).

Como sucedió en el verbo resultar, deberse (a) podía admitir argumento humano metonímico en el complemento, ${ }^{11}$ aunque esta posibilidad es relativamente tardía: se remonta al siglo XVII y no ha dejado demasiadas huellas en el corpus hasta el siglo $\mathrm{XX}$, momento en que se ha difundido con mayor fuerza en el discurso (contrariamente a lo sucedido con su sinónimo resultar):

Por lo que mira a las grandes ventajas que logró en las guerras con los príncipes vecinos, aquellas se debieron a los excelentes generales que tuvo (Benito Jerónimo Feijóo, 1750).

También es tardía la incorporación de oraciones subordinadas completivas, sobre todo en función de complemento. Los primeros ejemplos son del siglo XIX y se irán ampliando a medida que nos acerquemos a la época actual:

Según cuenta Zorrilla, la idea de escribir las leyendas, a lo menos en forma sistemática, se debió a que cierto día don Salustiano Olózaga le propuso componer un romancero con las hazañas de los bandidos del siglo XIX, y él, rechazando este proyecto, por parecerle indigno de su musa, resolvió en cambio emprender un legendario histórico y religioso (José Zorrilla, 1837-1840).

Por el contrario, deberse (a) no parece haber aceptado con facilidad los predicados expresados por medio del infinitivo verbal. Los ejemplos que nos ofrece el corpus son escasos y relativamente tardíos (siglo XIX):

Favila, hijo del anterior, heredó la corona por voluntad de su padre; pero no estaba a la altura que las difíciles circunstancias reclamaban, y tal vez se debe a estar los moros ocupados a la sazón en la conquista de las Galias, que no derrotaran a este monarca, más aficionado a la caza que a la guerra (Pilar Pascual de San Juán, 1888-1923).

11 Conviene no confundir el uso de deberse (a) como operador causativo converso dotado de complemento humano con su utilización más frecuente, al menos desde el siglo XVII, como una variante de ciertos verbos de apoyo de acción con la intención de enfatizar el sustantivo predicativo. En esos casos, no hay ampliación del número de argumentos y, por lo tanto, no podemos considerar que esta forma verbal actúe como operador causativo converso: “...la conquista espiritual de toda la tierra adentro se debió a sus religiosos [...]” (Fray Antonio Tello, 1650). 
Hay que destacar que esta unidad léxica, a pesar de su tardía incorporación al paradigma de los operadores causativos conversos, se fue imponiendo en el uso con una fuerza inusitada, hasta el punto de superar, en la época moderna, a las formas más antiguas redundar y resultar; en la actualidad, se ha convertido en la más frecuente, tanto en contextos formales como no formales y apenas se ha visto sometida a restricciones de selección. Se combina con naturalidad sustantivos predicativos, que pueden reducirse fácilmente a humanos o humanos colectivos por metonimia, oraciones subordinadas completivas y, en menor proporción, oraciones de infinitivo, sobre todo en función de sujeto.

\section{LOS OPERADORES DE CARÁCTER METAFÓRICO}

Algunos operadores causativos conversos aún revelan el proceso de extensión metafórica que ha conducido a su creación. Se trata, sobre todo, de verbos de movimiento y, especialmente, verbos que expresan procedencia u origen. En la mente del hablante se ha identificado la causa con el punto de partida, y la consecuencia, con el destino (venir, provenir, proceder, derivarse o seguirse). Pero también tenemos verbos que parten de un significado básico de cambio de estado (engendrar o nacer). Algunos son verbos patrimoniales o semicultismos bastante antiguos que empiezan a utilizarse como operadores conversos bastante pronto.

\subsection{Con idea de movimiento.}

\subsubsection{Venir}

Para entender su uso como operador causativo converso, hemos de partir de un empleo anterior, relativamente temprano (siglo XIII), como verbo distribucional opuesto a otros verbos generales como dar o hacer con el significado de 'producir algo de un modo natural': ${ }^{12}$

E por esto es muy buena criança e dan los ganados mucha leche [...] (Anónimo, 1300-1344).

Venir, a partir de su significado básico de procedencia, pasó a seleccionar, invirtiendo su orden, los mismos sustantivos argumentales, que se interpretaron, en posición de sujeto, como el producto derivado de una cosa y, en posición de complemento, como la cosa que lo produce:

[...] quanta lech e manteca e queso vinier de ovejas e de vacas [...] (Anónimo, 1253).

Teniendo en cuenta estos antecedentes, se entiende que venir pudiera dar un salto más, un poco después, y se convirtiera en un verbo capaz de expresar la relación de causa-consecuencia que se deriva de dos realidades abstractas; en ese sentido, pudo actuar como operador converso de los operadores causativos directos de la época, entre los que se encontraban también dar y, sobre todo, hacer (García Pérez 2007: 37-41).

12 He tratado específicamente de la evolución de este significado en García Pérez (2007: 136-140). 
Las primeras estructuras oracionales seleccionadas, en función de sujeto, fueron las constituidas por sustantivos predicativos de estado. Se trata de una selección léxica muy temprana, pues se remonta, al menos, al siglo XIII:

Acabdelladamjente quanto mas ffecho de armas. que es cosa tan peligrossa onde pueden venjr tantos males ssi sse non ffazen como deuen (Alfonso X, 1260).

Los ejemplos se volverán especialmente abundantes, sin embargo, a partir de los siglos XIV y XV:

Labrando nueuamente algund onbre en su heredad obra porque se destaiasse el agua que solia correr por ella \& viniendo de aquesta labor daño o perdida a otro alguno que ouiesse heredad açerca de aquella [...] (Anónimo, 1491).

Un poco más tarde se producirá una ampliación a sustantivos de acción y acontecimiento (siglo XIV):

[...] quando vieron el peligro que podrie venjr dela batalla vinieron todos al Rey don garçia \& Rogaron le mucho homjldosamente que les diese lo suyo (Anónimo, 1325).

En el caso del complemento de régimen, la selección de sustantivos predicativos fue, desde el principio, muy amplia, como parecen confirmar los ejemplos anteriores, en los que encontramos los predicados labor (acción) y pleito (acontecimiento). El sustantivo causa, con valor un tanto redundante, empezó a aparecer en función de complemento desde finales de la Edad Media:

Estas cosas vistas alleguemo nos a la curacion cerca la diuersidad delas causas. Pues si viniere de causas primitiuas: o por enfermedades manifiestas curen se aquellas por su contrario [...] (Anónimo, 1495).

La preposición que introduce el complemento pudo variar en algunos momentos, aunque algunas recciones son muy limitadas en el tiempo. Un caso interesante es el de la preposición en; la idea de procedencia, por su parte, explica que el adverbio relativo donde haya podido utilizarse para recuperar el núcleo del complemento:

[...] e en cobdiciar omne la muger agena e quebrantar el casamiento limpio de la guisa que Nuestro Señor Dios le vieda aquí, nin fazer otro ayuntamiento de varón e de mugier vienen muchos males [...] (Alfonso X, 1275).

También encontramos ejemplos con la preposición por desde sus primeros empleos como operador, preposición que tendrá un gran éxito a lo largo del tiempo, pues se conserva ininterrumpidamente hasta nuestros días:

Que deve saber la tu merçed que quanta carestía, e mal, e daño viene a la tierra es por los que conpran para revender, quel labrador forçado ha de vender (Anónimo, 1237).

Desde el siglo XVI, el verbo admitió oraciones de infinitivo que no sólo siguieron siendo posibles durante toda la historia de nuestra lengua, sino que han llegado 
hasta la actualidad; de hecho, pueden considerarse especialmente frecuentes en las variedades menos formales de la lengua:

Pedro Sarmiento le requirió por escrito de parte de Vuestra Majestad no lo hiciese, protestándole el daño que viniese de no poblar por salirse de allí a fuera, y no estimó el requerimiento [...]

También a partir del siglo XVI empezó a difundirse el uso de oraciones subordinadas completivas:

Diráme alguno por ventura queste desenfrenamiento de la lengua viene de que permite Dios que para castigo de aquéllos hablen (Bernardo Pérez de Chinchón, 1533).

Es evidente que, por su gran extensión en la lengua general como verbo de movimiento, venir arraigó con fuerza en el paradigma de los operadores causativos conversos y se ha mantenido en el uso hasta nuestros días, quizá con mayor vigor que cualquiera de los anteriores.

\subsubsection{Provenir}

Muy ligado al verbo venir se halla provenir, cultismo tomado del latín PROVENIRE en el siglo XV y usado, casi de inmediato, como operador causativo converso. Los primeros ejemplos se remontan a la primera mitad de esa centuria, ya con una selección muy variada de sustantivos predicativos en posición de sujeto (acción, estado o acontecimiento):

A aquellos que en el amor derechamente paran mientes non ay al mundo mal e crimen que dél non se sygua o puede ser; por quanto, como suso dixe, dél provienen muertes, adulterios e perjuros [...] (Alfonso Martínez de Toledo, 1438).

También en el caso del complemento, los sustantivos predicativos seleccionados fueron muy variados y, como hemos visto en otros operadores causativos conversos, fue posible que oraciones de infinitivo y oraciones subordinadas completivas desempeñaran esta función en la misma medida (estas últimas un poco más tarde que las de infinitivo):

[...] é como este numero de grados no solo no se contenga en las dichas navegaciones, mas antes falten casi 50 grados, no se puede otra causa dar, salvo que proviene de ser mayor la distancia oriental de lo que hobieron ellos asi manifestado [...] (Anónimo, 1524).

No estuvo excluida la utilización de sustantivos humanos o asimilables a los humanos (Dios, Demonio, etc.) con valor metonímico:

[...] y ansí, aunque no por parte del Spíritu Sancto ni de Cristo proviniese impedimento, habíale por parte de los discípulos [...] (Fray Dionisio Vázquez, 1530-1539).

Aunque, al igual que sucedía en el resto de los operadores causativos conversos, la preposición más habitual en el complemento era de, encontramos algunos ejemplos (puntuales) de la preposición por, independientemente de la categoría gramatical del núcleo, quizás en un intento de reforzar el sentido causativo del segundo elemento: 
[...] y el que la beve queda tan sediento después de averla bevido como antes, señaladamente quando la sed proviene por abundancia de calor (Francisco Franco, 1569).

[...] pidiéndoles servicio personal de los indios para recompensa y satisfacción de la paga de sus tributos, lo cual todo proviene por no se hacer las pagas en los tiempos que están señalados [...] (Anónimo, 1573).

Este uso preposicional fue, sin embargo, bastante efímero; no se extendió más allá de los Siglos de Oro. Se puede decir, por tanto, que la estructura sintáctico-semántica de provenir como operador causativo converso quedó fijada en el siglo XVII y se ha mantenido, sin demasiados cambios, hasta nuestros días.

\subsubsection{Proceder}

El verbo proceder es también un cultismo, muy cercano al anterior desde el punto de vista semántico. Sin embargo, como forma verbal apareció relativamente pronto, pues encontramos ejemplos desde el siglo XIII con el sentido de 'avanzar' o 'pasar adelante', heredado directamente del latín. Como operador causativo converso empezó a utilizarse solo un poco después (siglo XIV, al menos), y manifestó una cierta preferencia, en estos momentos iniciales, por los sustantivos predicativos de estado en posición de sujeto, que se irán ampliando a los restantes (acción y acontecimiento) a partir del siglo XV:

[...] assi los jouenes deuen emperar mas aquellas cosas que son de lohar, porque la honor proçede mas ayna de las buenas costumbres que de la ualerosa ropa (Juan Fernández de Heredia, 1379-1384).

También a partir de esta centuria final de la Edad Media empezó a admitir el verbo oraciones subordinadas de infinitivo y oraciones completivas, incluso en coordinación con sustantivos predicativos: ${ }^{13}$

[...] muchas vezes las hablan con las mugeres o moças de casa. y alg[uno]s alcança[n] parte a ellas. y de aqui proçeden los furtos a los señores y muchas vezes tratar delos matar y rreçebir otras deshonras (Anónimo, 1400-1500).

En el caso del complemento, proceder seleccionó sustantivos predicativos precedidos de la preposición de, como se puede apreciar en el primer ejemplo recogido más arriba, y no resultó raro que estos sustantivos fueran sustituidos por humanos o asimilables a estos (Dios, Demonio, etc.) con valor metonímico:

El qual es dios glorioso. del qual proçede toda ssapiençia \& toda çiençia \& todo bien. ssegunt costantjno jn terçio ssue pratiçe jn prinçipio (Estéfano de Sevilla, 1400).

La selección de oraciones de infinitivo y oraciones subordinadas completivas, en este caso, es un poco más tardía. Hemos de esperar hasta finales del siglo XV para encontrar los primeros ejemplos.

Esta coordinación tenderá a desaparecer cuando la Retórica imponga con mayor fuerza el gusto por una cierta homogeneidad sintáctica. 
El no poder responder procedía de que a la sazón votábamos en la Inquisición el negocio de las brujas de Navarra, y el no querer salía de enviarme a pedir cosa tan peregrina, con la cual si vos, señor, tomábades gusto en leerla, yo me enojaba y aun me cansaba en buscarla (Fray Antonio de Guevara, 1521-1543).

Se puede afirmar, pues, que la estructura sintáctico-semántica de proceder, como la de provenir, es bastante amplia y quedará fijada relativamente pronto; se va a mantener, principalmente en los textos formales, hasta la actualidad, a pesar de mostrar una cierta preferencia en nuestros días por los sustantivos predicativos (frente a oraciones de infinitivo o completivas en función de complemento).

\subsubsection{Derivarse}

Este verbo, tomado tempranamente del latín DERIVARE (s. XIII, DECH) ${ }^{14}$, empezó a utilizarse como operador causativo converso en el siglo XV, al igual que la mayoría de los miembros de este grupo. Paralelamente a sus sinónimos, seleccionó, en primer lugar, sustantivos predicativos de estado en posición de sujeto:

La razon de la diversidad era que el baptismo que este onbre resçibio ante de la passion de Cristo nunca tovo su heficaçia fasta la passion de Cristo, porque de ella se deriva en todos los sacramentos la virtud [...] (El Tostado, 1437).

A partir del siglo XVI el corpus refleja la extensión a otros sustantivos predicativos:

[...] porque el fundamento de la sabiduría y buen orden en las cosas nacen del amor y del temor de Dios y de allí se derivan todos los buenos sucessos de los mortales (Cristóbal Mosquera de Figueroa, 1583-1596).

En lo que respecta al complemento, la selección de sustantivos predicativos fue la más habitual durante los siglos XV, XVI y XVII, y es posible encontrar sustantivos humanos en sentido genérico con valor metonímico:

Vos, Señor, sois el hermoso, y de Vos se deriva y mana toda la hermosura que yo tengo, no por cierto comparada con la vuestra, sino en cuanto criatura levantada por Vos en dignidad tan alta como es la de amiga y esposa (Fray Juan de los Ángeles, 1607).

La selección de oraciones subordinadas de infinitivo o completivas queda reflejada en el corpus más tardíamente que en el caso de otros operadores causativos conversos. Los primeros ejemplos son del siglo XVIII. A pesar del paso del tiempo, no han sido nunca demasiado abundantes:

Tiene la Nobleza principio de la virtud de alguno de nuestros mayores, pero la generosidad se deriva de no degenerar de aquella primera naturaleza (Antonio Palomino y Velasco, 1724).

En la actualidad, siguiendo esta tendencia sintáctico-semántica general del verbo, se prefieren los sintagmas cuyo núcleo está constituido por un sustantivo predicativo $\mathrm{y}$, solo en bastante menor medida, oraciones subordinadas completivas.

14 Los ejemplos que encontramos en el CORDE, sin embargo, no van más allá del siglo XV. 


\subsubsection{Seguirse}

El verbo patrimonial seguir, en su forma pronominal, con un sujeto y un complemento precedido de la preposición de, entró a formar parte de los operadores causativos conversos en el siglo XIII, aunque empezará a extenderse con más fuerza por los textos a partir del siglo XIV. Como había sucedido con los restantes miembros del grupo, los primeros ejemplos muestran una selección de sustantivos predicativos de estado en posición de sujeto:

De los males que se siguen de la cobdicia carnal (Juan Fernández de Heredia, 1376-1396).

A partir del siglo XV asistimos a una extensión paulatina a otro tipo de sustantivos predicativos (acción y acontecimiento):

Puesto que lo suso dicho sea verdad segun los theologos canonistas, non plaze a los teologos que ninguna irregularidat sea quitada por el baptismo, ca, como por el baptismo sean los pecados perdonados solamente $\&$ aquello que se sigue dellos, la irregularidat nin es pecado nin se sigue de pecado, antes muchas de bezes de obra meritoria [...] (Anónimo, 1450).

El sujeto, como hemos visto en el caso de otros operadores causativos, podía estar constituido por oraciones. Los ejemplos más antiguos son de la misma época:

La segunda es, a saber, que son vergonzosas, porque son temerosas; ca por cuanto ellas tanto son temerosas que casi de toda cosa han pavor, bien se sigue de esto que son vergonzosas, porque, como ya dije, vergüenza no es sino un temor de recibir mengua (Fray Martín de Córdoba, 1468).

También a partir del siglo XV, aunque los ejemplos no empiezan a ser más abundantes hasta una centuria más tarde, el operador seguirse admite complementos en infinitivo:

[...] y por los daños que se siguen de traer la ropa de los lugares de la comarca donde su (fol. 378v) corte residía, no entendía de mandar que se truxese ropa alguna, pudiéndose escusar (Alonso de Santa Cruz, 1491-1516).

La selección de oraciones subordinadas completivas en función de complemento, por su parte, se remonta al siglo XVI; se trata de una estructura especialmente frecuente durante los Siglos de Oro, pero que entrará en decadencia en el siglo XVIII:

Otrosy, dezimos que por yspiriençia claramente se vee el dapno que [Anterior]se sygue de que Vuestra Magestad mande dar salarios ni ayudas de costa a los alcaldes de chançilleria en penas de cámara, porque claramente se vee por ysperiençia que condenan en mas penas de dineros de los que condenarian, y otras vezes comutan penas corporales en dineros por ser pagados dellos [...] (Anónimo, 1537).

En la actualidad, el verbo seguirse conserva, sobre todo, la selección de sustantivos predicativos tanto en función de sujeto como de complemento; puede admitir también complementos en infinitivo, aunque el número de ejemplos es 
bastante más reducido. ${ }^{15}$ En cuanto a las oraciones subordinadas completivas, parece que el proceso de decadencia iniciado en el siglo XVIII se ha acentuado, hasta el punto de que hoy en día, al menos en la lengua formal, el verbo no admite fácilmente este tipo de construcciones. ${ }^{16}$

\subsection{Con idea de cambio de estado.}

Se trata de verbos que implican, originalmente, una idea de cambio de estado, pero que, en su paso a la función de operadores causativos conversos, parecen vincularse a un sentido metafórico de “origen” o "procedencia”.

\subsubsection{Engendrar}

El verbo engendrar, semicultismo del latín INGENERARE, es bastante antiguo en español. Los primeros ejemplos se remontan a principios del siglo XIII y, como tuve ocasión de mostrar en García Pérez (2007: 33-35), entró a formar parte del paradigma de los verbos que estaban vinculados a la idea de 'producir' en sentido amplio y que seleccionaban un complemento humano ('procrear'); se trata de un paradigma fundado por el verbo hacer en el siglo XII.

- ¡Merced vos pedimos, padre, sí vos vala el Criador!

Vós nos engendrastes, nuestra madre nos parió; $(\mathrm{Cid})^{17}$

A partir de este significado, y como consecuencia de un proceso metafórico, se desarrolló, muy tempranamente, un sentido causativo directo:

[...] por rrazon que nasçe en oriente e este viento engendra / e cria muchas njeues (Anónimo, 1223).

En este caso, pues, la existencia de esta primera construcción causativa fue un aliciente para la constitución de una variante causativa conversa (ya en el mismo siglo XIII) por pronominalización de la forma básica y alteración en el orden de los elementos (consecuencia-causa). Hemos de tener en cuenta que, en la variante pronominal inicial, estaba muy presente la idea de 'origen' o 'procedencia'. Al transformarse en operador, la preposición introductora del complemento pudo ser la preposición por, lo cual, como hemos visto más arriba, no estaba excluido de otros miembros de esta clase sintáctico semántica:

E engendran-se los saberes en el ome por aprender luengo tienpo, e engendran-se las buenas maneras por usar buenas costumbres (Anónimo, 1250).

15 Aunque no encuentro ejemplos en el CORDE más allá de comienzos del siglo XX, sí aparecen algunos en el CREA que es necesario tener en cuenta.

16 No encuentro ejemplos ni en el CORDE (s. XX) ni en el CREA.

17 Podríamos adelantar la fecha de introducción de este verbo en castellano hasta el siglo XII solo si aceptamos la teoría de Menéndez Pidal sobre la escritura del Poema de Mío Cid. 
Esta estructura preposicional no fue, sin embargo, la más habitual, al menos en los primeros siglos de su andadura, aunque se ha mantenido en el uso hasta nuestros días:

[...] para otros, la crisis se engendra por los desequilibrios que generan fundamentalmente el agotamiento de los mecanismos de regulación (CREA, 1990).

La preposición más habitual fue, como en sucedió en el caso de los restantes operadores causativos conversos, de, que se conservó con mucho vigor hasta el siglo XVIII:

[...] e dizen que Venus fue engendrada en la mar porque la luxuria se engendra de grande habundancia de deleytes (Clemente Sánchez de Verdial, 1420-1421).

En principio, engendrarse seleccionó, en función de sujeto y complemento, sustantivos predicativos; pero, frente a lo sucedido con otros operadores, las oraciones subordinadas en función de complemento no han tenido éxito en ningún momento de la historia. Los ejemplos son tardíos (desde el siglo XVII) y muy aislados.

Malos jueces han de ser, y es muy natural que se dejen arrastrar de la pasión y cariño que se engendra de vivir y criarse juntos, y que den el voto por su colegial (Manuel Lanz de Casafonda, 1761).

Este operador entró en franca decadencia a partir del siglo XVIII, aunque nunca llegó a desaparecer. Esta decadencia llevó aparejada también, curiosamente, la de la preposición de como unidad introductora del complemento de causa: en los escasos ejemplos con que contamos en la época actual, la preferencia por la preposición por es claramente mayoritaria. ${ }^{18}$

\subsubsection{Nacer}

El verbo nacer se prestó desde muy temprano a interpretaciones metafóricas, de ahí que no resulte tampoco sorprendente su conversión en operador causativo converso. En este caso, no contamos con una variante causativa directa previa, lo que no es de extrañar, pues el verbo nacer, introducido en castellano como verbo de aparición, se ligaba con mucha facilidad a una cierta idea de origen o procedencia. Su uso como operador consecutivo es bastante antiguo. Al igual que en el caso de engendrar, los primeros testimonios se remontan al siglo XIII:

Como de mala çepa naçen malos grañones, naçen de este viçio viçiosas crïazones: maldiguezas, tristiçias e otras traïçiones; despiertas cada día con malos aguijones. (Libro de Alexandre, 1240-1250).

18 Me baso en el CREA para esta afirmación. 
$\mathrm{Al}$ igual que en el caso de los restantes operadores, si los sustantivos predicativos de estado fueron los que primero asumieron las funciones de sujeto y complemento, los sustantivos de acción y acontecimiento no dejaron de cumplirlas un poco más tarde.

[...] otrosí porque ningún peligro non pudiese arebatadamente nacer de la cibdat de Tuscula -con la qual, comoquier que ellos non oviesen guerra abierta, todavía estavan en dubda e en sospecha- por ende fueron fechos cónsules Valerius Publius, que lo avía seydo por quatro vezes, e Titus Lucrescius, que avía estado una (Pero López de Ayala, 1400).

Las oraciones subordinadas de infinitivo o completivas tampoco se hicieron esperar en posición de sujeto:

[...] e fázense ý muchos e grandes pecados, e nacen ende muy grandes desamores, e dubdas de fijos, e yerros de parentescos, e heredar a fijos agenos, e casamiento sin ley e errados non lo sabiendo los parientes, e grandes enemiztades [...] (Alfonso X, 1275).

En función de complemento, el uso de este tipo de oraciones se remonta al siglo XVI, al menos, y se prolonga hasta nuestros días:

[...] y esta diferencia no nació de que entonces se falló el oro y después se descubrió el hierro, ni aun porque faltan en esta nuestra edad sabios, sino porque sobran en ella maliciosos (Fray Antonio de Guevara, 1529-1531).

En la actualidad, el verbo nacer, como operador causativo converso, sigue siendo uno de los más utilizados de nuestra lengua. Su estructura es aún muy amplia, pues admite tanto sustantivos predicativos de carácter general como oraciones subordinadas de infinitivo y oraciones completivas.

\section{CONCLUSIÓN}

El presente artículo ha mostrado la importancia de tener en cuenta un grupo concreto de verbos dentro de los llamados operadores causativos: los operadores causativos conversos u operadores consecutivos. Se trata de un conjunto de operadores estrechamente vinculados a los causativos que enriquecen la expresión de las relaciones causales a lo largo de la historia de la lengua.

Desde el punto de vista sintáctico-semántico, estos verbos comparten una misma estructura: seleccionan predicados en función de sujeto, interpretados como una consecuencia, y en función de complemento de régimen, interpretados, a su vez, como la causa que da lugar a esa consecuencia. Este complemento, en casi todos los casos -exceptuando, únicamente, el verbo deber- lo introduce la preposición de y, con menos frecuencia, la preposición por.

Desde el punto de vista histórico, los operadores causativos conversos son el resultado de distintos procesos de metaforización, procesos que no siempre resultan perceptibles en la actualidad o, al menos, no en la misma medida. Su aparición en 
español está muy ligado a su origen; los verbos patrimoniales más generales, e incluso los semicultismos, en los que la idea de origen o procedencia resulta más marcada, son los operadores más antiguos, aunque no necesariamente los más opacos; los primeros testimonios se remontan al siglo XIII, momento en que los textos escritos empiezan a revestir una mayor abstracción. Pero el enriquecimiento definitivo del paradigma se produce en los siglos XIV y XV. Es en este periodo, en que aumenta la complejidad textual, cuando se introduce en la lengua un gran número cultismos semánticamente proclives a transformarse en operadores. Como hemos tenido ocasión de comprobar, la mayoría de ellos se han mantenido en el uso hasta nuestros días.

\section{OBRAS CITADAS}

Alfonso Vega, M. 2006. Verbos causativos. Sintaxis histórica de la lengua española. Dir. C. Company Company. México: UAM-Fondo de cultura económica. 971-1052.

Cano Aguilar, R. 1999. Los complementos de régimen verbal. Gramática descriptiva de la lengua española. Dirs. I. Bosque y V. Demonte. Madrid: Espasa. 1807-1854.

García Pérez, R. 2005. “¿Desde cuándo se cometen delitos? Relaciones entre léxico y sintaxis en la evolución histórica de la lengua del derecho penal.” Palabras, norma, discurso. En memoria de Fernando Lázaro Carreter. L. Santos Río, J. Borrego Nieto, J. F. García Santos, J. J. Gómez Asencio, y E. Prieto de los Mozos (Eds). Salamanca: Universidad de Salamanca. 509-519.

2006. "El proceso de formación de las clases léxicas y su importancia para un diccionario histórico: el ejemplo de la clase <odio>”. BRAE 56: 317-332.

2007. ¿Qué hacíamos y qué hacemos? El verbo hacer en la historia del español. San Millán de la Cogolla: Cilengua.

Gross, G. 1987. Les constructions converses du français. Paris: Droz. . 1993. "Les passifs nominaux". Langages 109: 103-125.

. 1996. "Prédicats nominaux et compatibilités aspectuelle”. Langages 121: 54-72.

. 2001. “Existe-t-il des verbes supports de type Etre Prép ?”. Par monts et par vaux. Itinéraires linguistiques et grammaticaux. Mélanges de linguistique générale et française offerts au professeur Martin Riegel pour son soixantième anniversaire par ses collègues et amis. C. BURIDANT, G. KLEIBER, J. C. PELLAT (Eds.). Louvain: Peeters. 197-204. . 1981. "Les bases empiriques de la notion de prédicat sémantique”. Langages 15: 7-52.

Náñez Fernández, E. 1995. Diccionario de construcciones sintácticas del español. Preposiciones. Madrid: Universidad Autónoma de Madrid.

Pascual, J. A. y García Pérez, R. 2007. Límites y horizontes en un diccionario histórico. Salamanca: Diputación de Salamanca. 